\title{
ENSINO DE LÍNGUAS ESTRANGEIRAS: A POESIA COMO RECURSO DIDÁTICO
}

\section{Gustavo FIGLIOLO*}

- RESUMO: O presente trabalho tem como objetivo fazer uma análise da utilizaçáo da literatura, com ênfase na poesia, como recurso didático no ensino de línguas estrangeiras (LE). A análise está baseada na contribuição teórica de alguns textos importantes sobre a temática que mostram quando, por que e de que forma é possível o uso da poesia para esse fim. Levantam-se alguns problemas quanto à utilização inadequada do texto literário nas aulas de E/LE, assim como uma enumeraçáo de argumentos a favor e contra o uso da poesia com essa finalidade. Sugere-se, finalmente, um possível caminho de abordagem metodológica que contemple a poesia como instrumento para o ensino de LE.

- PALAVRAS-CHAVE: Ensino-aprendizagem de LE. Literatura. Poesia. Abordagem metodológica.

\section{Introdução}

O presente artigo tem como objetivo fazer uma análise acerca das possibilidades de utilização da poesia como instrumento didático na aula de língua estrangeira (LE). Apesar da enorme riqueza que a literatura e a poesia dentro desta oferecem para o trabalho do ensino de LE em sala de aula, percebe-se que o campo não é muito aproveitado; pelo contrário, são pouquíssimos os manuais didáticos que exploram esta possibilidade de ensino.

A partir disto, entáo, faz-se uma revisão teórica acerca da literatura e o ensino de línguas estrangeiras (LE); traça-se um histórico da recorrência e os altos e baixos do ensino da literatura e o ensino desta como disciplina obrigatória da grade curricular; comenta-se a respeito do ensino da literatura como segunda língua; fala-se da necessidade da não desvirtuação do texto literário para sua utilização única e exclusiva com fins linguísticos (em exercícios de morfologia e sintaxe), atentando para a fragmentação e descontextualização que normalmente se faz do mesmo; explica-se a importância da literatura como veículo social e cultural, uma vez que reflete o mais representativo da cultura de um povo: seus costumes, sua tradição e sua visão de mundo; e frisa-se

\footnotetext{
* UEL - Universidade Estadual de Londrina. Departamento de Línguas Estrangeiras Modernas. Londrina - PR - Brasil. 86057-970 - gustavo@uel.br.
} 
a condição de autenticidade do texto literário, que transmite uma ideia que não foi concebida para o ensino da gramática, mas sim para sua fruição estética.

Com respeito especificamente à poesia e sua utilização como instrumento didático na aula de LE, faz-se uma enumeração de argumentos a favor e contra esta prática; na verdade há uma contra-argumentação a favor daqueles tópicos negativos mostrando que o uso da poesia na aula de LE pode ser absolutamente viável e eficiente.

\section{Orientações Curriculares do Ensino Médio e literatura}

As Orientações Curriculares do Ensino Médio (BRASIL, 2005) no capítulo Conhecimentos de Literatura visam ratificar a importância da mencionada disciplina dentro da grade curricular. Estas começam perguntando o porquê do ensino da Literatura no Ensino Médio, e traçam um histórico da mesma, no qual se verifica que a disciplina já gozou de um status privilegiado como um dos pilares da formação burguesa de uma elite letrada, para concluir que atualmente seu papel encontra-se relegado a um papel secundário dentro do conjunto das disciplinas.

Constata-se esta situação, também, no que concerne à utilização da literatura no ensino de LE a qual se vê relegada, na maioria dos casos, a um simples elemento decorativo e de viés "cultural" no final das unidades dos livros didáticos. Isto é, embora exista boa quantidade de material literário a disposição, as atividades propostas na maioria dos livros didáticos não visam a valoração do literário, da literatura, e sim estão maioritariamente focadas no trabalho das estruturas linguísticas, como gramática e vocabulário. Assim, o olhar está dirigido para a exploraçâo dos componentes linguísticos dos textos literários e não para a literatura per se. Existem, é verdade, teorias mais ou menos recentes, como a elaborada por McRae (1991), para quem o texto literário provê oportunidades para experiências ligadas diretamente aos sentidos e à imaginaçáo dos alunos. $\mathrm{O}$ autor considera essa linguagem como representacional, a diferença da linguagem meramente referencial que somente transmite informaçóes. Nesse sentido, a literatura provocaria uma atividade cerebral passando pelas próprias sensaçóes do indivíduo: emoção, êxtase, angústia, prazer, dor etc. A diferença com os métodos tradicionais estaria em como se comunicar e não o que comunicar. Porém, o que se constata é que, mesmo nos materiais didáticos mais avançados, há uma tendência a propor a leitura de um conto e analisá-lo desde a compreensão textual (características das personagens, desenvolvimento do enredo etc.), e não, por exemplo, a destacar as figuras de linguagem ou a riqueza da utilização estética dos vocábulos.

Este fato estaria dado em consequência dos atuais tempos "hipermodernos", uma modernidade elevada a uma potência superlativa, onde o foco não mais está no conjunto, mas na individuação, com a inerente determinação do mercado, numa cultura consumista que prega a velocidade e a insaciabilidade. Conforme Bauman (2001, p. 84), houve uma mudança do mundo moderno para o pós-moderno; na contemporaneidade, "o estatuto da incerteza [...] não é mais o temporário que deve ser superado; o incerto, 
doravante, é o permanente irredutível". Bauman define a situação do homem moderno como de "identidades instantâneas" ou "identidades de palimpsesto". O autor define assim essa cultura consumista:

No mundo dos consumidores as possibilidades são infinitas, pois o volume de objetivos sedutores à disposição nunca poderá ser exaurido. As receitas para boa vida e os utensílios que a elas servem tem data de validade, mas muitos cairão em desuso bem antes dessa data, apequenados, desvalorizados e destituídos de fascínio pela competição de ofertas novas e aperfeiçoadas. (BAUMAN, 2001, p. 84).

Nesse sentido, a literatura exige um "parar para pensar", uma "digestáo" lenta e precisa de sua estética, em detrimento do utilitarismo pragmático do hic et nunc.

Em defesa da literatura, o texto toma a mesma como uma arte: a de construir com palavras, servindo para educar a sensibilidade com vistas a transcender o dado empírico numa operação que permita, através da fruição estética, alcançar um conhecimento não mensurável, humanizando assim o homem coisificado. Como afirma Culler (1999, p.39-40):

Para Immanuel Kant, o principal teórico da estética ocidental moderna, a estética é o nome da tentativa de transpor a distância entre o mundo material e espiritual, entre um mundo de forças e magnitudes e um mundo de conceitos. Objetos estéticos, tais como as pinturas ou as obras literárias, com sua combinação de forma sensorial (cores, sons) e conteúdo espiritual (ideias), ilustram a possibilidade de juntar o material e o espiritual. Uma obra literária é um objeto estético porque, com outras funçōes comunicativas inicialmente postas em parênteses ou suspensas, exorta os leitores a considerar a inter-relação entre forma e conteúdo. Os objetos estéticos, para Kant e outros teóricos, tem "uma finalidade sem fim". Há uma finalidade em sua construção: são feitos de modo que suas partes operem conjuntamente para algum fim. Mas o fim é a própria obra de arte, o prazer na obra ou o prazer ocasionado pela obra, não algum propósito externo.

Citam-se as Leis de Diretrizes e Bases da Educação Nacional de 1996 (BRASIL, 1996), que em seu artigo 35, página 51, aponta como um dos objetivos, quanto à literatura, o de "aprimoramento do educando como pessoa humana, incluindo a formação ética e o desenvolvimento da autonomia intelectual e do pensamento crítico". Coloca-se uma citação de Antonio Candido que destacaremos por sintetizar o conceito de humanização já referido:

Entendo aqui por humanização [...] o processo que confirma no homem aqueles traços que reputamos essenciais, como o exercício da reflexão, a aquisição do saber, a boa disposição para com o próximo, o afinamento das emoçóes, a capacidade de 
penetrar nos problemas da vida, o senso da beleza, a percepçáo da complexidade do mundo e dos seres, o cultivo do humor. A literatura desenvolve em nós a quota de humanidade na medida em que nos torna mais compreensivos e abertos para a natureza, a sociedade, o semelhante (CANDIDO, 1995, p. 249).

O objetivo final é o de "formar o leitor literário ou, melhor ainda, de 'letrar' literariamente o aluno" (BRASIL, 2005, p. 54). Esse letramento constitui, segundo Soares (2003 p.47), o "estado ou condiçâo de quem não apenas sabe ler e escrever, mas cultiva e exerce as práticas sociais que usam a escrita”.

Constata-se, no âmbito escolar, a quase ausência da leitura de literatura, devido a sua substituiçáo por todo tipo de texto (resumos, compilaçóes, etc.), que não o texto literário, afastando a possibilidade de ampliação de horizontes, a reflexão, a educação da sensibilidade. Diante da necessidade do texto literário, é legítimo e mister perguntar-se o que é literário. Mais uma vez citaremos Antonio Candido:

Em nossa sociedade há fruição segundo as classes na medida em que um homem do povo está praticamente privado da possibilidade de conhecer e aproveitar a leitura de Machado de Assis ou Mário de Andrade. Para ele, fica a literatura de massa, o folclore, a sabedoria espontânea, a cançâo popular, o provérbio. Estas modalidades são importantes e nobres, mas é grave considerá-las como suficientes para a grande maioria que, devido à pobreza e à ignorância, é impedida de chegar às obras eruditas (CANDIDO, 1995, p. 256-257).

Assim, a confusão quanto à determinação da obra "erudita", contrastada com a literatura de massas, pode ser superada considerando o pensamento gramsciano, que observa uma diferença entre valor cultural e valor estético. Voltando a Culler (1999, p. 29), ele explica isso dizendo que "é tentador [...] concluir que a literatura é o que quer que uma dada sociedade trata como literatura - um conjunto de textos que os árbitros culturais reconhecem como pertencentes à literatura”. Porém:

Registrada dessa maneira numa página, cercadas por margens intimidadoras de silêncio, (a sentença) pode atrair um certo tipo de atenção que poderíamos chamar de literária: um interesse pelas palavras, suas relaçôes umas com as outras, e suas implicaçôes, e particularmente um interesse em como o que é dito se relaciona com a maneira como é dito. Isto é, registrada dessa maneira, essa sentença parece conseguir corresponder a uma certa idéia moderna de poema e responder a um tipo de atenção que, hoje, é associada à literatura. Se alguém dissesse essa sentença a você,, você perguntaria, "o que você quer dizer?", mas se você considerar essa sentença como um poema, a pergunta não é exatamente a mesma: não o que o falante ou autor quer dizer mas o que o poema significa? Como funciona essa linguagem? O que essa sentença faz? (CULLER, 1999, p. 31-32). 
É com base nestes pressupostos que faremos uma extensão da crítica e a consideraremos válida também para o ensino da literatura dentro do ensino de línguas não como mero enfeite, mas sim defendendo uma metodologia que ultrapasse uma visão que toma à literatura como simples ator coadjuvante dentro da estrutura linguística; a literatura é, em si, um universo que constitui a própria língua, que determina as possíveis variáveis das estruturas linguísticas, que alicerça o discurso qualquer que seja, e não uma instância exemplificadora destas estruturas linguísticas de que falamos; a literatura não surge para pôr em prática as regras sintáticas, semânticas e morfológicas de uma língua; a literatura justamente desafia estas regras e a análise que dela se faz transita outros caminhos que os da língua, caminhos próprios da condição literária. Embora seja possível verificar em textos literários, narrativos ou poéticos, como a estrutura da língua funciona, é inaceitável utilizar a literatura somente para esta tarefa; quando menos esteriliza a literatura e extrai dela seu verdadeiro valor, a corrompe e aniquila, deixando de ser literatura. O que sugerimos, então, é tratar e analisar a literatura em sua condição de tal, em sua riqueza semântica, como transmissora de uma mensagem, como articuladora e referente das épocas históricas, como ato comunicativo que o aluno possui para ampliar seu vocabulário e seus recursos expressivos e principalmente para tentar incorporar o acervo cultural da língua e utilizá-lo em sua interação social. Uma das autoras que defendem esta postura teórica é Sanz (2000, p.25):

La literatura debe enseñarse desde la conciencia de que es un valor social que nos permite familiarizarnos con el componente cultural de una determinada área neosocial. La literatura alimenta la lengua y es el espacio privilegiado en el que se reflejan comportamientos y hábitos de la vida cotidiana. ${ }^{1}$

As OCEM fazem uma crítica dos Parâmetros Curriculares Nacionais para o Ensino Médio, de 2002, resumida em dois pontos básicos. O primeiro diz respeito à ênfase radical no interlocutor, deixando ao leitor o julgamento de se uma obra é literária ou não. Em segundo lugar, foca-se exclusivamente a história da literatura (classificações das correntes literárias) em detrimento do texto em si. Faz-se necessário, então, delimitar o conceito de fruição estética, o qual não pode se confundir com uma simples atividade lúdica. O conceito de fruição estética parte das ideias desenvolvidas por George Lúckacs, que considera a estética como enraizada (ou na busca de enraizamento) na vida cotidiana. Diferentemente de Hegel, para quem a arte surge como uma manifestação sensível da Ideia, para Luckacs são as atividades do dia-a-dia que determinarão o comportamento estético do homem. (FREDERICO, 2000).

\footnotetext{
"A literatura se deve ensinar desde a consciência de que é um valor social que permite nos familiarizarmos com o componente cultural de uma determinada área neo-social. A literatura alimenta a língua e é o espaço privilegiado em que se refletem comportamentos e hábitos da vida quotidiana." (SANZ, 2000, p.25, tradução minha).
} 
A fruição estética exige do leitor a capacidade de construção de significados a partir da visão de mundo que ele tem e numa renovada intertextualidade; quanto mais letrado literariamente, maiores as possibilidades de construção desses significados. Esta fruição estética deve, também, surgir da leitura individual, deixando-se para um segundo momento uma leitura coletiva.

Conforme o nível de escolaridade, a literatura observa variações dentro do currículo escolar. No Ensino Fundamental, esta se caracteriza por uma composição menos sistemática e mais aberta; e fora do âmbito escolar, pelos livros chamados de literatura infanto-juvenil e toda sorte de obras que inicialmente chamam a atenção pelo título sugestivo ou a capa atraente. Mas, dentro da escola, as escolhas obedecem a variadas razóes, levando em consideração as variaçóes socioeconômicas de cada comunidade, o mercado editorial, os catálogos das editoras e a influência legitimada das autoridades no assunto que definem o que é bom e quais livros devem servir como suporte didático.

No Ensino Fundamental, entáo, os alunos leem da maneira que eles podem e conforme o que lhes é oferecido. Assim, não é raro encontrarmos a maioria das escolas sem bibliotecas ou com bibliotecas em situaçóes precárias. Desta maneira, o aluno só lerá, no melhor dos casos, o pouco que o professor lhe oferecer.

Já no Ensino Médio, as escolhas seguem os manuais didáticos, cujo principal problema é o da fragmentaçáo em trechos das obras, causando um deslocamento do contato direto entre o leitor e o texto literário, originando, segundo Osakabe e Frederico (2004 apud BRASIL, 2005, p. 62-3), três principais situaçôes problemáticas:

- A substituição da Literatura difícil por uma Literatura considerada mais digerível;

- A simplificação da aprendizagem literária a um conjunto de informaçôes externas às obras e aos textos;

- A substituição dos trechos originais por simulacros, tais como paráfrases ou resumos.

Diante desta situação, o que deve ser feito é proclamar a insubstituível leitura de livros. Neste sentido, será necessário não perder de vista duas situaçóes importantes: em primeiro lugar, o manuseio do livro não só abre a mente para um mundo de pensamentos, como também constitui um estímulo que se retroalimenta permanentemente, em um círculo virtuoso; em segundo lugar, apesar de as novas tecnologias serem de inegável importância, sua utilização não pode entender-se como uma substituição da prática da leitura por meio de livros.

O livro didático pode, evidentemente, servir como elemento de apoio, mas a leitura integral e original da obra literária precisa acontecer. As condensaçóes, excertos e resumos que são feitos das obras literárias extraem do original sua riqueza de conjunto e é preciso evitá-los.

Isto posto, precisaremos delimitar e significar a leitura literária. Esta leitura tem o epicentro no leitor, no encontro do livro com o leitor, que acarretará uma dimensão 
polifônica, no sentido bakhtiniano da dimensão dialógica do texto, sua pluralidade discursiva, a leitura múltipla e as diferentes vozes surgidas da intertextualidade.

Deve-se aclarar, no entanto, que as possibilidades de interpretação são limitadas pela fidedignidade de tal interpretação. Umberto Eco, citado pelas “Orientaçôes”, considera:

A leitura das obras literárias nos obriga a um exercício de fidelidade e de respeito na liberdade de interpretação. Há uma perigosa heresia crítica, típica de nossos dias, para a qual de uma obra literária pode-se fazer o que se queira, nelas lendo aquilo que nossos mais incontroláveis impulsos nos sugerirem. Não é verdade. As obras literárias nos convidam à liberdade de interpretação, pois propóem um discurso com muitos planos de leitura e nos colocam diante das ambigüidades e da linguagem da vida. Mas para poder seguir neste jogo, no qual cada geração lê as obras literárias de modo diverso, é preciso ser movido por um profundo respeito para com aquela que eu, alhures, chamei de intençáo de texto (ECO, 1989 apud BRASIL, 2005, p.67).

Assim, a leitura do texto literário provoca reaçóes e experiências diversas conforme cada leitor, daí a necessidade da leitura individual e pessoal para a formação do pensamento crítico.

$\mathrm{Na}$ escola, o pensamento crítico deve começar com o questionamento dos métodos utilizados na veiculação da literatura; sabemos que os textos assim chamados de best-sellers não são suficientes para que o aluno estabeleça um padrão crítico; da mesma maneira, a prática escolar em relação à literatura esbarra na metaleitura, isto é, a desconsideração do texto em si e a leitura de outros aspectos como, por exemplo, a contextualizaçáo histórica. O desafio, então, será o de achar os textos literários que, lidos em sua íntegra, originem o gozo da leitura e o prazer estético desse acontecimento, superando a nociva aparente necessidade e uma leitura rápida, imediata e consumista. Assim, comenta Candido:

Em nossa sociedade há fruição segundo as classes na medida em que um homem do povo está praticamente privado da possibilidade de conhecer e aproveitar a leitura de Machado de Assis ou Mário de Andrade. Para ele, ficam a literatura de massa, o folclore, a sabedoria espontânea, a canção popular, o provérbio. Estas modalidades são importantes e nobres, mas é grave considerá-las como suficientes para a grande maioria que, devido à pobreza e à ignorância, é impedida de chegar às obras eruditas. (CÂNDIDO, 1995, p. 256-257).

Por outro lado, sabemos que o professor exerce uma verdadeira mediação nas escolhas dos textos, no sentido de que determina (ou pode determinar) que material será utilizado. Mas o professor também está amarrado aos tempos escolares, aos gêneros e aos autores, em termos de currículo. Esse modelo, evidentemente, não favorece uma formação de consciência crítica, haja vista sua automatização. Na orientação do processo 
de seleção de leitura, deveriam ser considerados dois pontos essenciais: o primeiro diz respeito a uma seleçáo de obras e autores a serem lidos integralmente ao longo do processo; depois, a elaboração de projetos que levem o aluno a ler, além dos textos do "acervo básico", outros textos, visando à elaboração de seu pensamento crítico.

Embora o cânone literário não seja em si negativo, este deve ser constantemente reelaborado para a formação de uma tradição, mas não de maneira estática. Aqui será necessária a constante formação literária dos professores, cuja qualificação e capacitação permitirão que não se vejam submetidos a, por exemplo, uma lista de livros obrigatórios com vistas ao vestibular. Nas escolhas, a centralidade deve estar focada na obra literária; não que o contexto histórico social, político e cultural não seja importante, mas que sirva para o aprofundamento do estudo da obra e não como um fim em si; deve ser somente um meio (BRASIL, 2005).

Outro ponto de destaque é o do valor moral que as obras devem ter, o qual não pode estar atrelado a valores unicamente de determinados grupos, considerando dessa maneira um cânone que seria exclusivamente masculino, ocidental e cristão.

Considerando o tempo ao que o professor inevitavelmente se verá submetido, é extremamente importante que sejam verificadas as diferentes exigências de cada gênero em particular: romance, conto, crônica etc. No caso de um romance, por exemplo, requererá planejamento do professor para orientar a leitura e tempo para o aluno ler o livro. A fruição estética depende também do tempo que tanto professor quanto aluno dispóem. Um leitor letrado literariamente (com boa bagagem de leitura prévia de textos literários), assimilará muito mais facilmente as ideias veiculadas em uma obra, as marcas enunciativas das entrelinhas do texto, as mensagens implícitas, podendo avançar de maneira adequada com o objetivo da leitura; da mesma maneira, um professor que tenha lido muitos livros e que conheça muitas obras, provavelmente poderá saber quais são mais adequadas para a leitura e em que momento, conforme a disponibilidade de tempo

Quanto ao espaço, faz-se necessário um sistema de troca contínuo do mesmo, visando aos ambientes de leitura e circulação de livros que estimulem o ato da leitura: bibliotecas com um bom acervo e diferentes espaços dentro da própria escola.

\section{A não utilização do texto como pretexto}

Continuando a análise, cremos útil comentar as críticas que Lajolo (1985) faz da utilização do texto literário em sala de aula, apontando os equívocos mais comuns que o desvirtuam como tal e propondo alternativas para trabalhá-lo sem que o mesmo se transforme em "pretexto" para quaisquer práticas didáticas em sala de aula.

Lajolo começa o ensaio definindo a condição existencial do texto, como o ponto de encontro entre o escritor e o leitor, no exercício individual e solitário da escrita e da leitura. É a partir deste pressuposto que a autora começa a crítica à má utilização do texto literário em sala de aula: no contexto escolar, a presença do texto se faz artificial, 
dados o caráter coletivo da aula e o incentivo a uma leitura orientada, direcionando gostos, pertinências, preferências, etc.

Pelo contrário, a tarefa a ser feita é a de tentar que o aluno estabeleça, como leitor, um ponto de encontro com o texto, sem interferências prévias, mas com orientaçóes do professor após a leitura, após o encontro real do aluno com alguma significação do texto; para isto, evidentemente, o professor deverá ser um bom leitor, no sentido da capacidade de extraçáo de inferências de novos significados que o texto pode prover, e que com o amadurecimento que traz a experiência como leitor poderá passar ao aluno, junto com a carga de incentivo que isto pressupóe.

Outro problema, segundo Lajolo, que costuma surgir ao se trabalhar com literatura em sala de aula, remete à pouca ou nenhuma afinidade que alguns textos provocam, tanto no professor quanto no aluno; é necessário, nestas situações, ter a capacidade, depois de uma sincera reflexão, de optar por, eventualmente, abandonar o texto em questão e continuar com outro; a sacralização do texto literário só faz com que prevaleça uma atitude autoritária de imposição em detrimento da sensibilidade; a dogmatização do texto constitui o primeiro passo para sua desfiguração.

Existe também a ocorrência, em não pouca medida, dos textos direcionados ao estabelecimento de certos tipos de comportamento, como comenta Lajolo, do "bom filho", o "bom aluno", o "pobre conformado", o "rico caridoso", etc. Evidentemente que tais textos colaboram enormemente para "anestesiar" o senso crítico dos alunos. Diante da perspectiva de ter que trabalhar com tais textos, o que se pode fazer é concentrar, talvez, as energias no estudo especificamente linguístico, em termos de metragem, silabação, figuras de linguagem, etc., desconsiderando a semântica pré-fabricada. Isto nos leva a supor que mesmo com textos ruins é possível fazer um bom trabalho.

Outra questáo também recorrente aparece nos textos escolares que se pretendem modelos da língua; costuma-se confundir o aluno com a ideia da existência de palavras "melhores" que outras, e com a eterna procura por sinônimos, em vez de rastrear a semanticidade das palavras e verificar a impossibilidade de substituição de umas por outras: contextualizadas as palavras, rápido não é a mesma coisa que veloz, assim como garoto não é igual a menino. E se com os vocábulos esse tipo de prática é bastante comum, as estruturas linguísticas extraídas dos clássicos costumam servir de exemplo para a fixação das normas gramaticais cultas. É necessário, então, contextualizar e dimensionar o discurso para discutir o limite histórico que uma norma culta possui, no sentido da diferença, muitas vezes abissal, entre o falar e o escrever.

Outro assunto delicado que o professor deve enfrentar, diz respeito aos programas preestabelecidos pela instituiçẫo educativa, dos quais não se pode fugir, aparentemente. A fiscalização não ocorre somente por parte da direção da escola: os próprios alunos das séries terminais do Ensino Médio cobram do professor, por exemplo, quais textos literários cairão no vestibular, reduzindo assim a margem de manobra que o professor deveria ter ao trabalhar com literatura. E não raro as diretrizes recomendam a presença de diversos gêneros textuais, como o artigo de jornal, a crônica, as letras de músicas. 
Não que estes instrumentos sejam improdutivos, mas não pode se perder de vista que o texto literário original, lido na íntegra, não é substituível, e que sua leitura frequente originará uma capacidade constante e crescente de atribuição de novas significaçóes dentro do texto, colaborando para a formação do leitor maduro.

É bastante comum, também, nos livros didáticos, a incidência de textos com exercícios chamados de compreensáo, integrando inclusive provas de vestibulares. Mas a compreensão de um texto, por si só, é muito pouco; precisa haver uma atribuição de significados construídos a partir de inferências e do diálogo polissêmico com outros textos e com a própria experiência de vida do leitor.

Uma questão presente no enfoque que se utiliza no trabalho com o texto em sala de aula é a utilizaçáo deste de maneira fragmentada e descontextualizada para o aprendizado das distintas correntes literárias da história da literatura. O bom professor é aquele que sabe que as subdivisões feitas em "ismos" são históricas e ideológicas, e em consequência comunica isto a seus alunos para a formação de uma consciência crítica que não engula os rótulos sem uma análise prévia, sob o perigo de o texto perder seu sentido original e, como corolário, ser forçado em sua interpretação semântica ou estilística. Devemse verificar com os alunos, os leitores do texto, as possíveis artificialidades que vêm já prontas e considerar o texto desde uma perspectiva mais ampla.

Nesse sentido, a entrega ao jogo do texto, ao prazer da criação das significaçóes que emanam da leitura, a viagem que emerge do contato com o texto literário, requererá da observância dos postulados analisados acima. Há tantos textos quantos leitores os leem, e uma atitude tendenciosa que limite a consciência crítica e a força da imaginaçáo implicará o postergar a aventura que surge do texto literário.

\section{A literatura como recurso didático no ensino de LE}

Apontada a importância do ensino da literatura de um modo geral, na formação do educando desde seus primeiros passos de seu letramento e apontados os equívocos mais comuns na delicada tarefa de ensinar literatura (a arte da leitura e fruiçáo do texto literário), propomos passar agora à instância mais específica de analisar a literatura como recurso didático no ensino de LE.

Um texto de suma importância que trata do assunto é o de Albaladejo García (2004), Marco Teórico para el Uso de la Literatura como Instrumento Didáctico en la Clase de $E / L E$, que apresenta uma visáo da atual situaçáo da literatura como recurso didático em sala de aula, visando aportar ideias e elementos que contribuam para o aprimoramento e uma utilização mais eficaz deste valiosíssimo instrumento no ensino de uma segunda língua.

Inicialmente, a autora traça o percurso da presença da literatura no ensino de Línguas Estrangeiras através do tempo. Isto nos leva à década de 50, em que o modelo gramatical fazia um uso extensivo da literatura, baseado na tradução, na memorização de regras gramaticais e na extração de amostras literárias consideradas 
de um nível elevado. Assim, a literatura possuía um papel preponderante no ensino de uma segunda língua.

Já na década de 60 e inícios dos anos 70 , o foco passou da gramática e tradução para uma visão estrutural, compreendida no sentido da interação entre todas as partes, onde os elementos isolados não dáo conta de explicar o complexo funcionamento de uma língua; aqui o todo não configura a soma das partes, mas estas se explicam contextualmente dentro de uma estrutura maior que é a própria língua. Neste modelo, a literatura é substituída pelas estruturas linguísticas e o vocabulário.

Os anos 70 trazem consigo os modelos nocional-funcionais, nos quais são utilizados os aspectos sociais da língua, mas mantendo o antigo patamar de corte estrutural dos aspectos linguísticos. Ainda a literatura permanece relegada e náo utilizada como recurso didático.

A partir dos anos 80, com a Abordagem Comunicativa, o processo de ensino aprendizagem se desloca de maneira notória e significativa para a linguagem falada e a competência comunicativa. A Linguística Aplicada recorre a outras disciplinas como a Psicolinguística e a Sociolinguística e começam a ser considerados elementos diferentes no aprendizado da L2, tais como a motivação do aluno, a interação em sala de aula, o aproveitamento de materiais didáticos diferenciados. Mas o caráter utilitário deste modelo, no qual o principal objetivo é comunicar-se, principalmente de maneira oral, faz com que a literatura seja novamente rejeitada como um elemento de utilização didática.

Chega-se assim, finalmente, aos anos 90, em que o panorama de ensino de línguas adquire um caráter marcadamente eclético, onde diversas disciplinas são bem-vindas na ajuda do processo de ensino: Sociologia, Informática e outras. A Literatura, neste contexto, ganha proporçóes de máxima atualidade, mas aparece como um apêndice encerrando as unidades didáticas e "sempre como mero traço ornamental, cultural e quase exótico, do qual não surgem propostas metodológicas a dialogar com as unidades didáticas" (NARANJO PITA, 1999, p. 4). Acquaroni (2004, p. 18), nesse sentido, comenta:

Já o fato de situar o poema no final da unidade está a nos revelar, em muitos casos, as dificuldades que esse material suscita ao professor para sua incorporaçáo real no desenvolvimento da aula: o poema fica assim relegado a uma posição de fechamento marginal, de exercício voluntário que geralmente e por motivos de tempo para o cumprimento da programação não se realiza nunca em sala de aula.

Portanto, parece necessário considerar a competência literária como parte da competência comunicativa, para que desta maneira transcenda a simples posição de "curiosidade cultural" dentro dos livros didáticos e passe a ocupar o valor real que tem, em termos de estruturas lingüísticas, em termos de riqueza de vocabulário, em termos de transmissão de valores sociais e culturais e como propagadora da visão de mundo 
de outras sociedades, aquelas que têm como língua materna nossa língua alvo. López Valero e Encabo Fernández (2007) afirmam:

Parece obvia pues la importancia de reivindicar la Didáctica de la lengua y la Literatura como disciplina emergente y fundamental para la construcción de una enseñanza de calidad que posteriormente repercuta en la sociedad. Desde nuestra perspectiva no es algo nueva la reflexión referida a la importancia del lenguaje en la vida de las personas, hasta el punto de apuntar la posibilidad de que todo lo humanos sea lingüistico. ${ }^{2}$

Nessa linha já comentada, do valor da literatura como articuladora e propagadora dos componentes sociais e culturais, Menouer Fouatih (2009, p.125) aduz que:

La literatura es una forma de comunicación por una parte y por otra un elemento social $y$ cultural con características propias, que juega actualmente un papel importante en la mayor parte de los enfoques de enseñanza de lenguas. ${ }^{3}$

$\mathrm{Na}$ segunda parte do artigo, Albaladejo García se pergunta a respeito de por que introduzir a literatura nas aulas de Espanhol como Língua Estrangeira (E/LE), e oferece cinco motivos.

Em primeiro lugar, pelo caráter universal dos textos literários. As temáticas tratadas amor, solidão, fé, velhice - são do alcance de todas as culturas e todas as épocas, pelo que é bem provável seja do interesse do aluno.

O segundo motivo apresentado pela autora radica no valor da literatura como material "autêntico". Isto significa que, ao momento de sua produção, a obra literária não é pensada com o intuito de ensinar uma segunda língua, fato que lhe confere uma autenticidade que outros textos não têm.

Em terceiro lugar, a literatura possui um inestimável valor cultural, transmissor de códigos e condutas do lugar ficcional onde se acha situada, representativa por sua vez da sociedade do país da língua em questáo.

A quarta razão para a inclusão da literatura nas aulas de língua estrangeira está determinada pela riqueza linguística dos textos literários. Isto é verificável na abundância de novo vocabulário, na diversidade de estruturas sintáticas e nas variaçóes estilísticas que normalmente não encontramos na língua falada. O leitor/aluno estrangeiro entrará num

\footnotetext{
2 "Parece óbvia, pois, a importância de reivindicar a Didática da língua e a Literatura como disciplina emergente e fundamental para a construçáo de um ensino de qualidade que posteriormente repercuta na sociedade. Conforme nossa perspectiva, não é nova a reflexão referida à importância da linguagem na vida das pessoas, até o ponto de assinalar a possibilidade de que todo o humano é linguístico." (LÓPEZ VALERO; ENCABO FERNÁNDEZ, 2007, traduçâo minha).

3 "A literatura é uma forma de comunicação por um lado, e por outro lado é um elemento social e cultural com características próprias, que cumpre atualmente um papel importante na maior parte das abordagens de ensino de línguas." (MENOUER FOUATIH, 2009, p.125, tradução minha).
} 
mundo novo que aumentará sua capacidade de visão da L2 como um todo, trazendo também consigo uma enorme bagagem didática para a exploração da expressão escrita.

Finalmente, a literatura possui o potencial de estabelecer uma empatia entre o texto e o leitor, na qual este frequentemente se envolve emocionalmente, cobrando assim sentido o que lê, o que se traduzirá numa maior e melhor aprendizagem. A autora comenta:

La literatura parece sacar a luz las emociones, de forma que el lector puede llegar a identificarse con un personaje, compartir sus pensamientos y sentimientos, transportarse figurativamente con las imágenes evocadas en un poema, etc., conectando de alguna manera su experiencia personal con el texto (ALBALADEJO GARCÍA, 2004, p.40). ${ }^{4}$

Após oferecer-nos as razóes de por que incluir a literatura como recurso didático nas aulas de LE, a autora discorre acerca de quais textos são apropriados para um trabalho mais eficaz. E aponta, para isso, seis razóes que resumiremos nos tópicos seguintes:

- Acessibilidade dos textos: refere-se à dificuldade lingüística, em termos de contemplação de distintos níveis conforme a proficiência de dada estudante;

- Textos significativos e motivadores: obras atraentes, interessantes e divertidas, que se aproximem das vivências e exigências dos próprios estudantes;

- Textos integradores de várias destrezas, e aqui a autora cita o Plano Curricular do Instituto Cervantes:

Um fator importante no processo de aprendizagem orientado em direção à comunicaçáo é o desenvolvimento integrado das destrezas de recepção e produção em contextos estabelecidos de forma natural, de maneira que a prática de uma destreza determinada seja relevante na hora de facilitar a prática das demais. (ALBALADEJO GARCÍA, 2004, p.44).

- Textos que ofereçam múltiplas formas de serem explorados: referindo-se a exercícios que permitam a interação dos alunos, as dramatizaçóes, os debates, atividades lúdicas, etc.;

- Textos que ofereçam conotaçôes sócio-culturais: é necessário entấo que, além das idéias, pensamentos e emoçôes do autor, haja uma contextualização histórica das sociedades e circunstâncias onde são produzidos esses textos;

- Textos íntegros originais: no sentido de que os textos resumidos, adaptados em termos de níveis de dificuldade, não refletem totalmente os valores culturais,

\footnotetext{
"A literatura parece trazer à luz as emoçôes, de forma que o leitor possa se identificar com uma personagem, compartilhar seus pensamentos e sentimentos, transportar-se figurativamente com as imagens evocadas em um poema etc., conectando de alguma maneira sua experiência pessoal com o texto". (ALBALADEJO GARCÍA, 2004, p.40, tradução minha).
} 
sociais e ideológicos da sociedade - e por extensão da língua - em que foram produzidos.

O texto de Albaladejo García oferece valiosíssimos elementos para se repensar o modo em que a literatura pode ser utilizada como instrumento didático nas aulas de Língua Estrangeira, à luz das mudanças históricas que a própria literatura sofreu nas diferentes abordagens de ensino.

\section{A poesia na aula de LE}

Dentro deste vasto universo que conforma a literatura encontramos, qual constelação luminosa, a poesia. E nos faz pensar a respeito do aproveitamento pedagógico dos textos poéticos como material didático ou, dito de outra maneira, por que usar a poesia na aula de língua estrangeira.

Quando se propóe a aplicação da poesia na aula de LE, surge sempre o controvertido tema de sua funcionalidade didática. Se a poesia tem sido pouco utilizada como recurso didático no ensino de línguas, devemo-nos perguntar por que, que dificuldades apresenta, e se este material é realmente pouco recomendável para este tipo de ensino. Martínez Cantón (2008), em seu texto La enseñanza de los contenidos culturales a través de la poesía, faz uma observação com respeito às dificuldades que a poesia apresentaria; poderíamos resumir as ideias da autora nos seguintes tópicos:

- Mensagem não natural. Efetivamente, uma das críticas que a poesia recebe é a de estar apartada do registro formal e quebrar muitas vezes as regras gramaticais, pelo que no poderia ser um modelo de língua para o aprendiz de L2;

- Linguagem não imediatamente prática. Normalmente se procuram textos que reflitam as necessidades práticas mais imediatas que o aluno pode ter na hora de se comunicar. A poesia, percebida como de um uso muito elaborado da linguagem, e sem aparente finalidade prática, se consideraria por fora destes textos;

- Gera inibição nos alunos. Os estudantes estão, em ocasiôes, pouco familiarizados com os textos poéticos inclusive em sua própria língua. O fato de que a poesia goze de certo prestígio e seja considerada como algo "intocável" do ponto de vista lingüístico e culturalmente muito elevado, faz com que o aluno apresente um excessivo respeito diante dela e não se atreva a trabalhar com liberdade;

- Excessiva dificuldade pelo léxico e as figuras retóricas utilizadas. Como comentado, a linguagem poética costuma incluir um léxico mais cuidado e utiliza recursos como a metáfora e imagens elaboradas; uma elaboraçáo maior do que na linguagem coloquial, dificultando sua compreensão;

- Só seria aplicável em níveis superiores, devendo esperar-se a que o aluno possua certa familiaridade com o idioma, um léxico mais amplo e que tenha cobertas 
as necessidades comunicativas mais imediatas, isto é, em níveis avançados ou superiores.

O que Martínez Cantón (2008) propóe, fazendo uma contra-argumentação lógica que rebate os pontos anteriores, são os seguintes pressupostos, aqui resumidos:

- A poesia é uma mensagem natural. A história da poesia se remonta à origem da civilização e se confunde com a origem da própria linguagem. Está ligada à oralidade e à música. Além disso, a poesia expressa sentimento no autor e se propóe criar sentimentos análogos no interlocutor. A poesia propóe um uso, diante da linguagem corrente, mais livre e criativo, e justamente por não estar amarrada às regras canônicas não se pode dizer que não é autêntica e não tem uma intenção comunicativa;

- Os textos que refletem situaçóes pretensamente comunicativas apresentam, com frequência, uma linguagem estandardizada e bastante fixa. Isto faz com que em muitas ocasióes sejam entediantes e sua aprendizagem seja mecânica e náo espelhe com naturalidade as interaçóes comunicativas. A poesia, mesmo não apresentando a utilização ordinária da linguagem, expressa, fundamentalmente, sentimentos, pelo que se pode dizer que o trabalho com textos poéticos pode ajudar o aluno com temas e situaçóes práticas do dia-a-dia.

- A poesia, com toda sua pluralidade, é ou pode ser linguagem coloquial, cotidiana, ou hermética e difícil, mas está sempre elaborada esteticamente e permite trabalhar com procedimentos cognitivos como a metáfora e a metonímia que estão na língua cotidiana e coloquial e que são muito produtivas em termos de comunicaçáo, podendo ajudar o aluno a ver e compreender o mundo dos falantes de uma comunidade e aceder à cultura da língua que se aprende.

- A opiniáo de que a linguagem figurativa e o léxico utilizado são demasiado complicados para os alunos é bastante freqüente; porém, não se deve esquecer que a linguagem metafórica é muito utilizada na vida cotidiana. Muitas expressôes se baseiam, de fato, em metáforas (sabem-se os perigos, por exemplo, de morar no "pé" de um morro). Não existe razão, assim, para pensar que o aluno estrangeiro terá dificuldades instransponíveis para entender estas metáforas e esta linguagem figurativa, desde que seja dosada de maneira gradual.

Os pontos anteriores têm a intenção de rebater o que seriam "dificuldades" do uso da poesia como recurso didático para o ensino de línguas. A seguir, Martínez Cantón (2008) propóe pontos visivelmente a favor da utilização deste instrumento em sala de aula, um resumo dos quais seriam:

- A poesia é material real. Isto é, diante dos textos criados especificamente para os alunos de língua estrangeira, que podem resultar artificiais ou falsos, a poesia 
tem uma intenção comunicativa real dirigida a qualquer leitor. Além disso, o material disponível é abundante e variado, pelo que podemos, e devemos ser muito seletivos;

- Por ser material autêntico, contém usos linguísticos que costumam postergar-se no ensino e que, no entanto, são necessaríssimos para a comunicaçãoo ordinária. Recursos estilísticos e mecanismos expressivos como a ironia, a argumentação, o humor, etc. são de uso comum na poesia pelo que esta amplia a consciência linguística do aluno desde o primeiro contato com os textos poéticos;

- Encontram-se nos textos poéticos grande quantidade de informação cultural e sociocultural que descansa no coletivo das tradiçóes, pelo que a utilização de uma variedade de textos oferecerá uma maior heterogeneidade, um ponto de vista mais aberto e amplo, e, portanto, mais real. Assim, a poesia pode servir como ferramenta para a aquisição das claves culturais da cultura que se está aprendendo (e ensinando);

- A literatura, e em particular a poesia, pode ser um material muito motivador. Por ser intelectualmente valorizada, pode acarrear a sensação de realização ao aluno que se defronta com ela e se propõe estudá-la. Um poema representa, além disso, e muito frequentemente, uma resposta emocional, pelo que sua relevância em termos pessoais e de subjetividade pode ser incomensurável.

Estes são alguns pontos que fazem da poesia, segundo Martínez Cantón, uma valiosíssima ferramenta para o ensino de L2. Adotá-los constituirá, seguramente, um bom ponto de partida para o sucesso no ensino de LE.

\section{Considerações finais}

O que nos propomos neste artigo foi mostrar, embora de maneira sucinta, as possibilidades, a viabilidade e a importância da utilizaçáo da poesia como ferramenta didática na aula de língua estrangeira.

Fizemos uma revisão dos pressupostos teóricos concernentes à literatura e ensino de línguas; vimos as sugestóes propostas pelas Orientaçóes Curriculares para o Ensino Médio e analisamos algumas posturas de autores renomados no assunto como Marisa Lajolo, María Dolores Albaladejo García e Clara Martínez Cantón. Dentro da abordagem metodológica considerando um viés literário, reservamos um espaço para comentar os prós e contras de por que ensinar uma LE por meio da poesia; nesse sentido, foi ressaltada a importância do ensino da poesia pela poesia em si, embora a mesma possa ser adaptada para o trabalho das estruturas linguísticas. Finalmente, cremos que uma reflexão sobre a argumentação feita neste trabalho permitirá ampliar os horizontes quanto às possibilidades dos tipos de abordagens metodológicas a ser utilizadas no ensino de LE, aproveitando nesse espaço as contribuiçóes que a poesia pode trazer. 
Sabemos que a poesia oferece um vasto campo a ser explorado e cremos que o trabalho com o texto literário, se bem orientado, pode responder às expectativas de estudantes e professores; abrindo portas para a viagem imaginária, estimulando o intelecto a deixar um registro da própria visão de mundo, regozijando a alma com a fruição estética, incitando os olhos a descobrirem as verdadeiras coisas de valor. $\mathrm{O}$ aluno que entre no espírito de um poema fará com certeza outro poema do mesmo, com toda a contribuição que isso traz tanto para ele como para a sociedade em que ele vive. Por termos essa convicção a respeito da importância da literatura e da fruição do texto literário, acreditamos que sua utilização como recurso para o ensino de LE se impóe como inadiável, procurando sempre a análise desde o literário especificamente por sobre a abordagem desde a estrutura linguística em termos de classes gramaticais.

\section{FOREIGN LANGUAGES TEACHING: POETRY AS A DIDACTIC RESOURCE}

- ABSTRACT: The following work aims to make an analysis about the use of literature, emphasizing poetry, as a didactic resource for the Foreign Languages (FL) teaching process. The analysis is based in the theoretical contribution of some important texts about the subject showing when, why and how it is possible the use of poetry to that means. Some problems are raised with respect to an inadequate use of the literary text in FL classes, as well as an enumeration of arguments for and against the use of poetry for that purpose. It is suggested, finally, a possible path of methodological approach considering poetry as instrument for FL teaching.

- KEYWORDS: FL teaching process. Literature. Poetry. Methodological approach.

\section{REFERÊNCIAS}

ALBALADEJO GARCÍA, M. D. Marco Teórico para el Uso de la Literatura como Instrumento Didáctico en la Clase de E/LE. Revista Eletrônica do Instituto Cervantes, São Paulo, n.7, p.37-43, Set. 2004.

ACQUARONI, R. La comprensión lectora. In: SÁNCHEZ LOBATO, J.; SANTOS GARGALLO, I. (Org.). Vademécum para la formación de profesores: Enseñar español como segunda lengua (L2)/ lengua extranjera (LE). Madrid: SGEL, 2004. p.789-810.

BAUMAN, Z. Modernidade Líquida. Tradução Plínio Dentzien. Rio de Janeiro: Zahar, 2001.

BRASIL. Orientaçôes Curriculares Nacionais para o Ensino Médio: Linguagens, Códigos e suas Tecnologias. Brasília: Ministério da Educação, Secretaria de Educação Média e Tecnológica, 2005. 
BRASIL. Lei no 9.394, de 20 de dezembro de 1996. Estabelece as diretrizes e bases da educação nacional. Diário Oficial, Brasília, 20 dez. 1996. Disponível em: <http://www.planalto.gov.br/ ccivil_03/leis/L9394.htm>. Acesso em: 13 set. 2016.

CANDIDO, A. Direito à literatura. In: CANDIDO, A. Vários Escritos. São Paulo: Duas Cidades, 1995. p.169-191.

CULLER, J. Teoria Literária: uma introdução. Tradução Sandra Vasconcelos. São Paulo: Beca Produçôes Culturais, 1999.

FREDERICO, C. Cotidiano e arte em Lukács. Estudos Avançados. São Paulo, v.14, n.40, p.299-308. set./dez. 2000.

LAJOLO, M. O Texto náo é Pretexto. In: ZIBERMAN, R. (Org.). Leitura em crise na escola: as alternativas do professor. Porto Alegre: Mercado Aberto, 1985. p.52-62.

LÓPEZ VALERO, A.; ENCABO FERNÁNDEZ, E. La Enseñanza de Conceptos en Lingüística Usando la Literatura Infantil. 2007. Disponível em: <http://www.unrc. edu.ar/publicar/borradores/Vol7/pdf/La\%20ensenanza\%20de\%20conceptos\%20en\%20 Linguistica\%20usando\%20la\%20literatura\%20infantil.pdf>. Acesso em: 10 set. 2016.

McRAE, J. Literature With a Small 'l'. London: Macmillan, 1991.

MARTÍNEZ CANTÓN, C. I. La Enseñanza de los contenidos culturales a través de la poesía. 2008. 112f. Disertación (Máster en Enseñanza del Espańol como Lengua Extranjera) Universidad Complutense de Madrid, Madrid, 2008.

MENOUER FOUATIH, W. La Literatura como recurso didáctico en el aula de E/LE. In: TALLER DE LITERATURAS HISPÁNICAS Y E/LE, 1., Madrid. Actas... Madrid: Centro Virtual Cervantes, 2009. p.121-130. Disponível em: <http://cvc.cervantes.es/ensenanza/ biblioteca_ele/publicaciones_centros/pdf/oran_2009/13_fouatih.pdf >. Acesso em: 15 set. 2016.

NARANJO PITA, M. La Poesía como Instrumento Didáctico en el Aula de Espańol como Lengua Extranjera. Madrid: Edinumem, 1999.

SANZ, M. La literatura en el aula de ELE. Revista Universitaria Frecuencia L, Madrid, v. I, p. 24-27, Jul. 2000.

SOARES, M. Letramento: um tema em três gêneros. Belo Horizonte: Autêntica, 2004

Recebido em ?

Aprovado em ? 